\title{
Diffuse Retinal Thickening due to Epiretinal Membrane in a Patient with Idiopathic Parafoveal Telangiectasia
}

\author{
(i) İgbal HAMZAYEV, iD Ahmet ELBAY, id Cansu EKINCİ, id Hakan ÖZDEMIR
}

Bezmialem Vakıf University Faculty of Medicine, Department of Ophthalmology, İstanbul, Turkey

\begin{abstract}
Idiopathic parafoveal telangiectasia (IPT) is characterized by abnormal dilated or ectatic retinal capillaries with exudation. In many studies macular hole or pseudohole was demonstrated in patients with IPT. However, only one case with the coexistence of IPT and epiretinal membrane (ERM) formation was reported before. In this study, we presented the retinal alterations of a patient with IPT admitted to our clinic with complaint of blurred vision for two months. A hyperreflective band refers to ERM, diffuse thickening and increased reflectance of inner retinal layers and cystic spaces in the inner nuclear layer of the retina were detected in horizontal optic coherence tomography (OCT) images of left eye. Due to the thickening of the inner retinal layers, foveal depression was lost. There was no full-thickness or partial-thickness retinal tissue defect in any OCT scan.
\end{abstract}

Keywords: Idiopathic parafoveal telangiectasia, epiretinal membrane, optic coherence tomography

\section{Introduction}

Idiopathic parafoveal telangiectasia (IPT) is characterized by abnormal dilated or ectatic retinal capillaries with exudation in one or both eyes. The term IPT was first used by Gass and Oyakawa (1) in 1982. The classification of the disease was established by Gass and Blodi (2) according to clinical and fundus fluorescein angiography findings. In following years, macular hole or pseudohole was demonstrated in patients with IPT in many studies $(3,4)$. However, only one case with the coexistence of IPT and epiretinal membrane (ERM) formation was reported before (5). In this case report, we presented ERM formation and related retinal alterations in a patient with IPT.

\section{Case Report}

A 82-year-old male was admitted with blurred vision of left eye for 2 months. He expressed that his right eye was blind due to a blunt trauma. The corrected best visual acuity in the examination of the patient who did not undergo any intraocular surgery was at the level of $6 / 10$ in the left eye and he could only see hand movement in the right eye. Severe corneal leukoma and vascularization were observed in examination of the anterior segment in the patient who had no systemic disease except hypertension. Lens could not be visualized due to leukoma. Nucleocortical lens opacification was observed in the left eye. Intraocular pressure was measured as $12 \mathrm{mmHg}$ in the right eye and $16 \mathrm{mmHg}$ in the left eye. Fundus examination could not be performed in the right eye. In the left eye, telengiectasias and small retinal hemorrhages were observed in the white-grey region, which was about 1.5 disc diameter in temporal area of the fovea. It was observed that the retinal vessels in the macula and in the described white-grey region were slightly pulled due to ERM (Figure 1). A hyperreflective band refers to ERM, diffuse thickening and increased reflectance of inner retinal layers and cystic spaces in the inner nuclear layer of the retina were detected in horizontal optic coherence tomography [(OCT), Spectralis, Heidelberg Engineering)] images of left eye. Due to the thickening of the inner retinal layers, foveal depression was lost (Figure 2). There was no full-thickness or partial-thickness

Address for Correspondence: Cansu EKINCi, Bezmialem Vakıf University Faculty of Medicine, 
retinal tissue defect in any OCT scan. It was observed in fundus fluorescein angiography that telengiectasias appearing in temporal area of the fovea in the left eye in the early period caused leakage in the late period. No choroidal neovascularization was observed (Figure 3).

Written and oral informed consents were taken from the patient. Written consent could not be attached because it was lost.

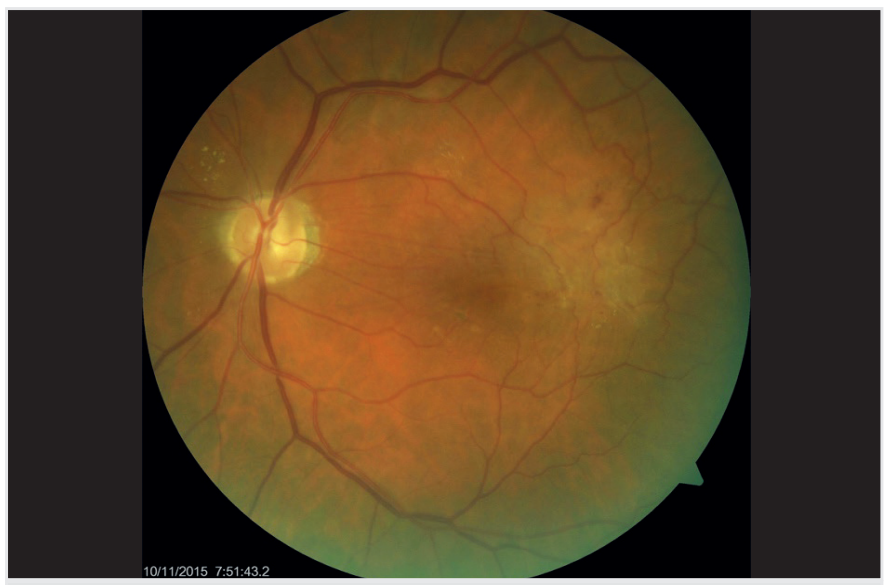

Figure 1. Colored fundus figure of the patient's left eye

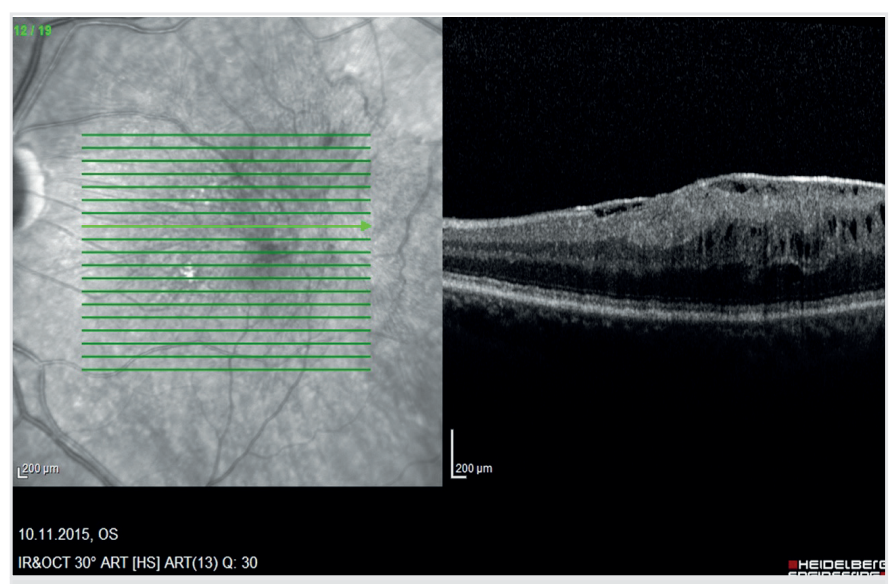

Figure 2. Horizontal optic coherence tomography image of the patient's left eye
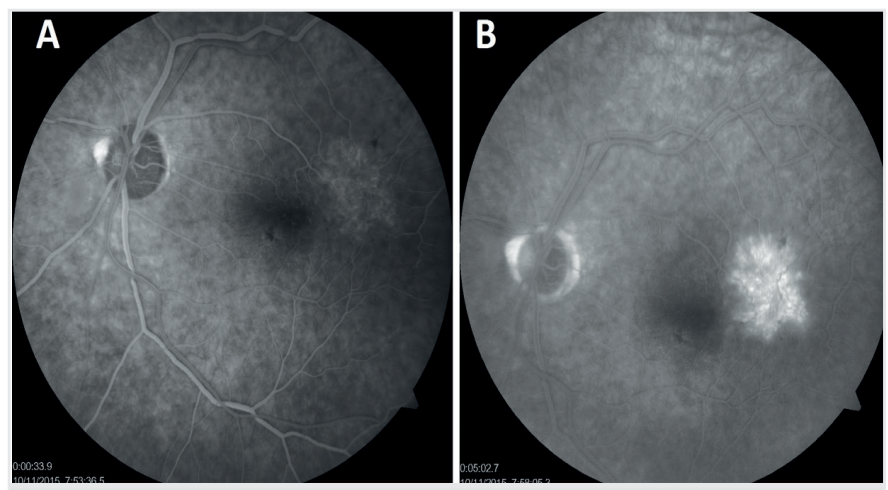

Figure 3. Fundus fluorescein angiography images of the patient's left eye in the early $(A)$ and late $(B)$ phases

\section{Discussion}

The pathophysiology of IPT is not fully understood. In the early studies, it was thought that retinal capillaries were primarily responsible for the disease, and in the subsequent studies, it was suggested that chronic liquid leakage could lead to metabolic deterioration and cell death, especially in Muller cells and photoreceptors (6). It was also suggested that chronic retinal ischemia may play role in Muller cell destruction (6). Muller cells have an astrocyte-like function; supporting nerve cells in the retina capillary endothelium and surrounding nerve cells, and extend from the photoresporter cell layer to the inner limiting membrane. Destruction of Muller cells in IPT is known to lead to the development of macular hole or pseudohole. There are many studies in the literature showing development of full-thickness or partial-thickness retinal tissue defects as well as macular holes or pseudoholes in patients with IPT (3). It was reported that in some of those patients, ERM accompanied macular hole or pseudohole. Diffuse retinal thickening was described in primary ERM before and it was described in ERM due to IPT only in one patient. In the article by Gomes et al., (5) a 46-year-old female patient with IPT was reported to have ERM and diffuse retinal thickening in both eyes and it was emphasized that their patient was the first patient with diffuse retinal thickening and ERM due to IPT reported in the literature. In that patient, diffuse thickening of the inner layers of the retina due to ERM in both eyes and large hyporeflective cavitation in the outer layers of the retina which suggested serous macular detachment were observed. In our patient, ERM and diffuse retinal thickening without any retinal tissue defect were observed. However, unlike in the patient reported by Gomes et al., (5) cystic cavities were detected in the inner nuclear layer of the retina in our patient. This is not usual in primary ERM. Probably, leakage from telangiectasic vessels caused cystic formations. It should also be kept in mind that, due to the patient's age, epiretinal membrane might not be secondary. The presence of cystic cavities that are not seen in patients with primary ERM and the presence of ERM, especially in the region of telangiectasic vessels support the relationship between ERM and IPT. But, only one patient reported in this case report is a limitation. Similar case series or studies with larger number of patients will provide more information.

\section{Ethics}

Informed Consent: Written and oral informed consents were taken from the patient. Written consent could not be attached because it was lost.

Peer-review: Externally peer-reviewed.

\section{Authorship Contributions}

Surgical and Medical Practices: H.Ö., İ.H., Concept: A.E., H.Ö., Design: H.Ö., A.E., Data Collection or Processing: İ.H., C.E., Analysis or Interpretation: İ.H., C.E., H.Ö., Literature Search: İ.H., C.E., Writing: İ.H., C.E. 
Conflict of Interest: No conflict of interest was declared by the authors.

Financial Disclosure: The authors declared that this study received no financial support.

\section{References}

1. Gass JD, Oyakawa RT. Idiopathic juxtafoveal retinal telangiectasis. Arch Ophthalmol 1982;100:769-80.

2. Gass JD, Blodi BA. Idiopathic juxtafoveolar retinal telangiectasis. Update of classification and follow-up study. Ophthalmology 1993; 100:1536-46.
3. Surguch V, Gamulescu MA, Gabel VP. Optical coherence tomography findings in idiopathic juxtafoveal retinal telangiectasis. Graefes Arch Clin Exp Ophthalmol 2007;245:783-8.

4. Özkaya A, Ünver YB, Acar N, Kapran Z. İki tip 2a jukstafoveal retinal telenjiektazi olgusunda fundus görüntüleme bulguları. RetVit 2012;20:146-50.

5. Gomes FV, Felix JPF, Nascimento MA, Lira RPC. Epiretinal membrane formation associated with idiopathic macular telangiectasia: case report. Arq Bras Oftalmol 2014;77:264-6.

6. Yannuzzi LA, Bardal AM, Freund KB, Chen KJ, Eandi CM, Blodi B. Idiopathic macular telangiectasia. Arch Ophthalmol 2006;124:450-60. 